\title{
Pengaruh Weight Training Terhadap Peningkatan Daya Ledak Otot Lengan
}

\author{
Dwipa Aprisandy ${ }^{1}$, Arie Asnaldi ${ }^{2}$, Nirwandi ${ }^{3}$ \\ ${ }^{123}$ Fakultas Ilmu Keolahragaan, Universitas Negeri Padang, Indonesia. \\ E-mail: dwipasandy12@gmail.com ${ }^{1}, \underline{\text { asnaldi@fik.unp.ac.id }}$, nirwandi@fik.unp.ac.id ${ }^{3}$
}

\begin{abstract}
Abstrak
Penelitian ini termasuk dalam penelitian eksperiment semu dan penelitian ini bertujuan untuk mengetahui seberapa besar pengaruh Weight Training menggunakan Bench Press terhadap daya ledak otot lengan atlet karate Pendidikan Olahraga Universitas Negeri Padang. Penelitian ini dilaksanakan pada bulan Maret sampai April 2019 di Gedung Labor FIK tepat nya di aula karate dan Fitnes Centre. Populasi dalam penelitian ini adalah seluruh atlet karate Pendidikan Olahraga Universitas Negeri Padang yang berjumlah 30 orang dimana sebanyak 22 orang atlet putra dan 8 orang atlet putri yang berusia 18-25 tahun dan sampel diambil berdasarkan teknik Purposive Sampling sebanyak 15 orang atlet putra dan putri yang berumur 18-20 atau Under 21. Untuk mendapatkan data penelitian digunakan tes Two Hand Medicine Ball Push. Data yang diperoleh dianalisis dengan uji t-test. Berdasarkan analisis data dalam penelitian ini menggunakan uji t-test. Hasil pengolahaan data dalam penelitian ini adalah: 1) diperoleh rata-rata (2.96) menjadi (3.48), artinya penerapaan Weight Training dengan bentuk latihan beban menggunakan bench press dapat menungkatkan daya ledak otot lengan ditandai dengan diperoleh $\mathrm{t}_{\text {hitung }}(5,1376)>\mathrm{t}_{\text {tabel }}$ (1.753), artinya penerapan Weight Training manggunakan Bench Press dapat meningkatkan daya ledak otot lengan atlet karate Pendidikan Olahraga Unverisitas Negeri Padang, dimana menunjukan hasil yang baik.
\end{abstract}

Kata Kunci: Latihan beban, daya ledak, lengan otot

\section{Abstract}

This research is included in the research pseudo experiment and this research aims to know how big the influence of Weight Training using Bench Press against the explosive power of the muscular arm of Karate Sports Education University of the State Padang. The study was conducted from March to April 2019 at the on-spot Labor building in the Karate Hall and fitness Centre. The population in this research is the all-athletes of the Padang State University Karate Sports Education which amounted to 30 people, of which as many as 22 men athletes and 8 women athletes aged 18-25 years and samples were taken based on techniques Purposive Sampling as many as 15 men and women from 18-20 or Under 21 athletes. To obtain the research data used Two Hand Medicine Ball Push test. The Data obtained is analyzed by the T-Test test. Based on data analysis in this study using T-Test test. The results of the data processing in this study are: 1) acquired average (2.96) to (3.48), meaning that the Weight Training in the form of weights exercises using bench press can tighten the explosive power of the arm muscles marked with the obtained Thitung (5.1376) > This (1,753), meaning the application of Weight Training manguse Bench Press can increase the explosive power of 
Sport Science: Jurnal Sain Olahraga dan Pendidikan Jasmani ISSN 114-562X (Cetak), ISSN XXXX-XXXX(Online)

http://sportscience.ppj.unp.ac.id/index.php/jss/index

the muscle of the athletes of Karate sports education Unverisitas Negeri Padang, which shows good results.

Keywords: Weight Training, explosive power, muscle arm

\section{PENDAHULUAN}

Pembangunan dibidang olahraga merupakan salah satu aspek penting dalam kehidupan masyarakat saat ini. Hal ini disadari sepenuhnya bahwa melalui olahraga akan meningkatkan prestasi, kesegaran jasmani serta pembentukan sikap yang sesuai dengan hakekat pembangunan manusia yang seutuhnya. Hal ini terdapat dalam UU RI No. 3 tentang sistem keolahragaan Nasional Bab II pasal 4 yang menyatakan bahwa:

"Keolahragaan Nasional bertujuan memelihara dan meningkatkan kesehatan dan kebugaran, kualitas, manusia menanamkan nilai moral dan akhlak mulia, disiplin, mempererat dan membina persatuan dan kesatuan bangsa, memperkukuh ketahanan bangsa, serta mengangkat harkat, martabat dan kehormatan bangsa (2005:6)".

Berdasarkan kutipan diatas, maka dapat diungkapkan bahwa untuk meningkatkan manusia yang berkualitas yang sadar akan petingnya kesehatan jasmani dan rohani adalah dengan melakukan aktifitas olahraga. Dalam rangka meningkatkan kontribusi olahraga sebagai salah satu upaya untuk meningkatkan kualitas sumber data manusia dan kegiatan olahraga yang dilakukan tidak hanya dalam memasyarakatkan olahraga dan mengolahragakan masyarakat, akan tetapi masyarakat Indonesia memiliki jiwa dan raga yang sehat serta kesegaran jasmani yang baik, juga untuk mencapai prestasi yang maksimal dalam kerja maupun olahraga.

Olahraga sangat berkembang pesat sampai saat ini. Terbukti dengan banyaknya timbul klub yang bergerak dibidang olahraga. Salah satunya adalah pada cabang olahraga karate. Olahraga cabang karate adalah olahraga yang menuntut aspek kekuatan, kecepatan, dan juga daya tahan kekuatan. Olahraga karate banyak melibatkan otot-otot ditubuh bahkan hampir seluruh otot tubuh, mulai dari otot jari, otot tangan, otot lengan, sampai dengan otot kaki, dalam olahraga cabang karate juga melibatkan faaktor lainnya yaitu keberanian, ketenangan, kelenturan tubuh, dan teknik yang benar.

Olahraga karate sudah lama berkembang di Indonesia sejak tahun 1972 yang dibawa oleh putra-putri Indonesia yang belajar di Jepang. Sekarang olahraga karate sudah mulai menampakan prestasi yang cemerlang pada event nasional maupun internasional. Olahraga dalam pembinaan atlet selalu menginginkan prestasi yang lebih tinggi untuk kejayaan bangsa dan negara. Untuk mencapai prestasi yang tinggi harus didukung dengan kematangan mental atlet, kedisiplinan atlet dalam latihan dan juga asupan gizi yang masuk kedalam tubuh para atlet tersebut dalam pencapaian prestasi yang tinggi. Pencapaian prestasi yang tinggi harus melalui metode latihan yang tepat, atlet yang berbakat, perencanaan yang matang dan pembinan kondisi fisik yang baik. Walaupun atlet karate Pendidikan Olahraga Universitas Negeri Padang sudah sering mendapatkan medali di banyak event perlombaan, tetapi masih saja terlihat belum maksimalnya pukulan para atlet.

Berdasarkan pemantauan peneliti yang juga anggota dari tim karate Pendidikan Olahraga Universitas Negeri Padang, perkembangan beladiri karate di Pendidikan Olahraga Universitas Negeri Padang dalam tiap-tiap pertandingan sering terjadi kelemahan pada saat melakukan pukulan terhadap lawan, hal ini dapat dilihat dari yang telah diikuti seperti tidak dapatnya point setelah melakukan pukulan kepada lawan, pukulan tidak tepat sasaran, teknik pukulan yang tidak sempurna dan pukulan mudah ditangkis oleh lawan. Semua itu diduga karen rendahnya daya ledak otot lengan yang mereka miliki. Oleh sebab itu, apabila hal ini terus dibiarkan dalam jangka waktu yang panjang, maka prestasi yang ditorehkan oleh atlet karate Pendidikan Olahraga Universitas Negeri Padang akan semakin menurun dan akan sulit bagi mereka untuk bersaing dijenjang yang lebih tinggi. 
Beladiri karate merupakan olahraga yang sangat rumit dan komplek. Karena sangat banyak faktor yang mempengaruhi untuk mencapai prestasi yang maksimal. Beladiri karate merupakan beladiri dengan menggunakan kaki dan tangan. "seperti halnya olahraga beladiri lain, beladiri karate juga mempunyai suatu pukulan yakni pukulan yang dilancarkan kedepan dengan ditumbukkan ke sasaran (Teknik Dasar Karate(Kihon), (Abdul Wahid, 2006:47)", oleh sebab itu, seharusnya seorang atlet karate harus menguasai teknik pukulan dengan baik yang mana yang mana teknik dasar dalam menyusun serangan sebelum terjadinya kesempatan untuk mendapatkan poin.

Tabel. 1. Daftar hasil kejuaraan karate U19-U23 UNP

\begin{tabular}{lllll}
\hline Tahun & Nama Kejuaraan & Emas & Perak & perunggu \\
\hline 2016 & Kejurnas di Politeknik & 3 & 1 & 4 \\
& UNAND & & & \\
2017 & Kejurnas di Solo & 2 & 5 & 3 \\
\hline
\end{tabular}

Bertolak dari uraian dan table prestasi diatas maka tampaklah permasalahan yang akan diteliti, bahwa dalam beladiri karate unsur daya ledak otot lengan mempengaruhi teknik pukulan atlet karate Pendidikan Olahraga Universitas Negeri Padang. Semakin bagus daya ledak otot lengan yang dimiliki seorang atlet, maka semakin bagus pula kekuatan dan kecepatan yang dikeluarkan atlet tersebut. Selain itu, bentuk latihan dalam melakukan pukulan ini juga sangat penting, karena latihan merupakan cara menyempurnakan gerakan dalam pukulan.

Jadi, daya ledak otot lengan sangat berhubungan dengan latihan dalam melakukan teknik pukulan pada pertandingan karate. Salah satu latihan yang dapat meningkatkan daya ledak otot lengan tersebut adalah dengan melakukan latihan Bench Press. Oleh sebab itu peneliti tertarik untuk mengetahui pengaruh Weight Training terhadap daya ledak otot lengan atlet karate Pendidikan Olahraga Universitas Negeri Padang.

Latihan beban menggunakan Bench Press adalah salah satu latihan beban yang melatih tubuh bagian atas yang bertujuan untuk merangsang dada dan lengan (Deltoid dan Trisep). Latihan ini berfokus kepada perkembangan otot besar dada yang mencangkup Deltoid depan, Serratus depan, Scapulae Fixers, Trapezii, dan Trisep. Bench Press adalah salah satu dari tiga alat pangangkat daya/tenaga yang digunakan secara ekstensif pada latihan berat yang bertujuan untuk pembentukan tubuh dan merupakan tipe latihan fitnesh untuk perkembangan dada dan lengan yang digunakan dalam latihan dalam setiap cabang olahraga, termasuk dalam olahraga karate.

Daya ledak otot lengan merupakan suatu kemampuan otot yang sangat penting diantara banyak komponen dasar kondisi fisik, oleh sebab itu latihan beban menggunakan Bench Press sangat berperan dalam daya ledak otot lengan. Apabila latihan beban tidak dilaksanakan, maka daya ledak otot lengan yang dihasilkan kurang baik juga.

\section{METODE}

Jenis penelitian ini eksperimen semu (quasi Experimental). Jenis penelitian ini eksperimen semu (quasi Experimental). Adapun latihan Bench Press merupakan variabel bebas, sedangkan daya ledak merupakan variabel terikat.Penelitian ini di laksanakan dengan menggunakan rancangan satu kelompok tes awal dan tes akhir (One Group Pretest Posttest Design). Untuk lebih jelasnya dapat di lihat pada bagian rancangan berikut: 


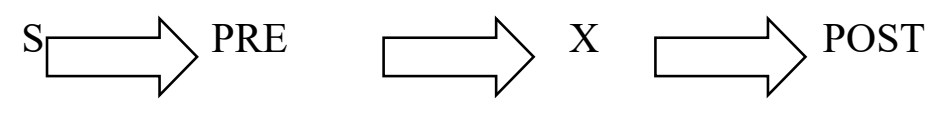

Gambar 1. Rancangan Penelitian

Adapun latihan Bench Press merupakan variabel bebas, sedangkan daya ledak merupakan variabel terikat.Penelitian ini di laksanakan dengan menggunakan rancangan satu kelompok tes awal dan tes akhir (One Group Pretest Posttest Design). Waktu penelitian pada bulan Maret-April 2019, sedangkan tempat penelitian di Labor Fitness Centre FIK-UNP. Teknik analisis data ini menggunakan statistik uji t (uji beda) .

\section{Alat dan Teknik Pengumpulan Data}

Untuk mendapatkan data dalam penelitian ini terlebih dahulu peneliti membuat beberapa langkah kerja:

\section{a. Pengumpulan Data}

Data ini didapat melalui tes two hand medicine ball push untuk mengukur daya ledak ototlengan.

\section{b. Instrumen Penelitian Daya Ledak Otot Lengan}

Menurut Barry L. Jhonson (1986:214) dalam (David Pratama, 2010: 32) "Untuk mengukur daya ledak tes yang digunakan adalah Two Hand Madicine Ball push dengan tingkat reliabilitas 0.84, validitas $0.77 \mathrm{dan}$ berat $6 \mathrm{lb}(1 \mathrm{~kg}=2.2046 \mathrm{lb})=2.72 \mathrm{~kg}$ ".

\section{Perlengkapan:}

1) Bola medicine

2) Kursi

3) Formulir tes

4) Kapur

5) Meteran

6) Stopwatch

\section{Pelaksanaan:}

Testee (atlet) duduk dikursi bersandar, tangan lurus dengan pandangan kedepan, pegang bola Medicine oleh kedua tangan tepat didepan dada, sampai bola menyentuh dada. Selanjutnya dilakukan mendorong bola dengan maksimal sehingga diperoleh jarak yang jauh.Pada saat mendorong bola badan harus tetap pada posisisnya, untuk itu dada ditahan dengan tali oleh pembantu tes yang lainnya. Testee diberi kesempatan sebanyak tiga kali, setiap kali melakukan pengetesan diberi interval waktu istirahat selama 30 detik sebelum melakukan berikutnya.

\section{Penilaian:}

Penilaian yang dicatat adalah jarak hasil lemparan bola medicine yang terjauh diukur menggunakan meteran dari ujung kaki bagian depan sampai titik jatuhnya bola yang dilemparkan. Untuk memudahkan pengukuran sebaiknya bola yang dilempar diolesi terlebih dahulu dengan kapur sehingga jatuhnya bola akan nampak di lantai. 


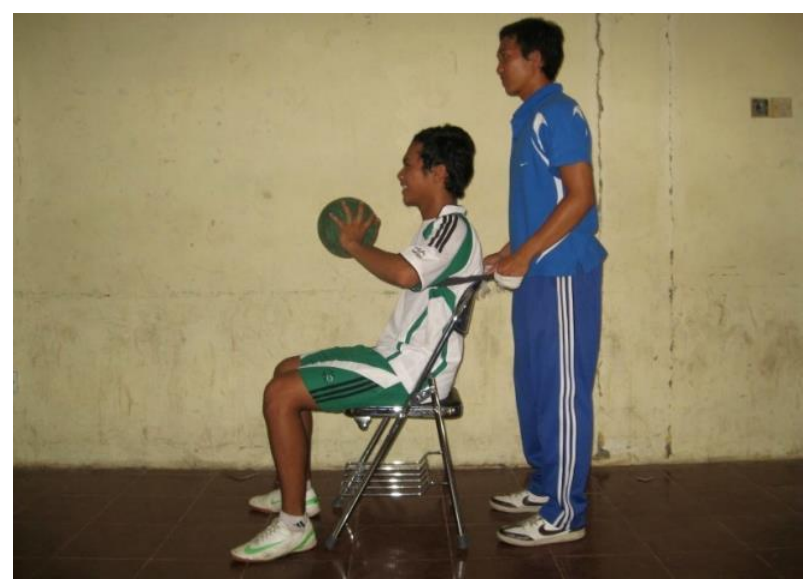

Gambar 2: Two Hand Medicine Ball Push Test

\section{HASIL DAN PEMBAHASAN \\ Hasil Penelitian}

Berdasarkan eksperimen yang dilakukan dan sesuai dengan uji-t variabel terikat maka terdapat dua unit analisis data dalam penelitian ini. Deskriptif data dari masing-masing unit analisis ini menunjukan hasil sebagai berikut:

\section{Data Daya Ledak Otot Lengan Atlet Karate Pendidikan Olahraga Universitas Negeri Padang (Pre Test).}

Berdasarkan analisa tersebut data tes awal maka pengaruh Weight Training terhadap daya ledak otot lengan atlet karate Pendidikan Olahraga Universitas Negeri Padang menunjukan hasil sebagai berikut: skor tertinggai 3.72 dan skor terendah 2.20 dengan rata-rata 3.06 dan standar deviasi 0.55 . Untuk lebih jelasnya akan di buatkan tabel distribusi frekuensi di bawah ini.

Tabel 2. Data Hasil Tes Awal Daya Ledak Otot Lengan Atlet karate Pendidikan Olahraga Universitas Negeri Padang.

\begin{tabular}{llcl}
\hline No & $\begin{array}{l}\text { Kelas Weight } \\
\text { Training }\end{array}$ & Frekuensi & Frekuensi \\
& $2.20-2.39$ & Absolut $(\mathrm{Fa})$ & Relatif $(\mathrm{Fr})$ \\
\hline 1 & $2.40-2.49$ & 3 & 20 \\
2 & $2.50-3.42$ & 5 & 13.33 \\
3 & $3.43-3.49$ & 2 & 33.33 \\
4 & $3.50-3.72$ & 3 & 13.33 \\
5 & Jumlah & 15 & 20 \\
& \multicolumn{2}{c}{ Berdasarkan data distribusi frekuensi di atas, persentase dari 15 orang sampel ternyata }
\end{tabular}
sebanyak 3 orang sampel (20\%) memiliki hasil daya ledak otot lengan dengan kelas Weight Training 2.20-2.39, kemudian sebanyak 2 orang sampel (13.33\%) memiliki daya ledak otot lengan dengan kelas Weight Training 2.40-2.49, selanjutnya ada sebanyak 5 orang sampel (33.33\%) memiliki daya ledak otot lengan dengan kelas Weight Training 2.50-3.42, sedangkan sebanyak 2 orang sampel $(13.33 \%)$ memiliki hasil daya ledak otot lengan dengan kelas Weight Training 3.43-3.49 dan sisanya 4 orang sampel lagi (26.67\%) memiliki hasil daya ledak otot lengan dengan kelas Weight Training 3.50-3.72. Untuk lebih jelasnya dapat dilihat pada Grafik berikut. 


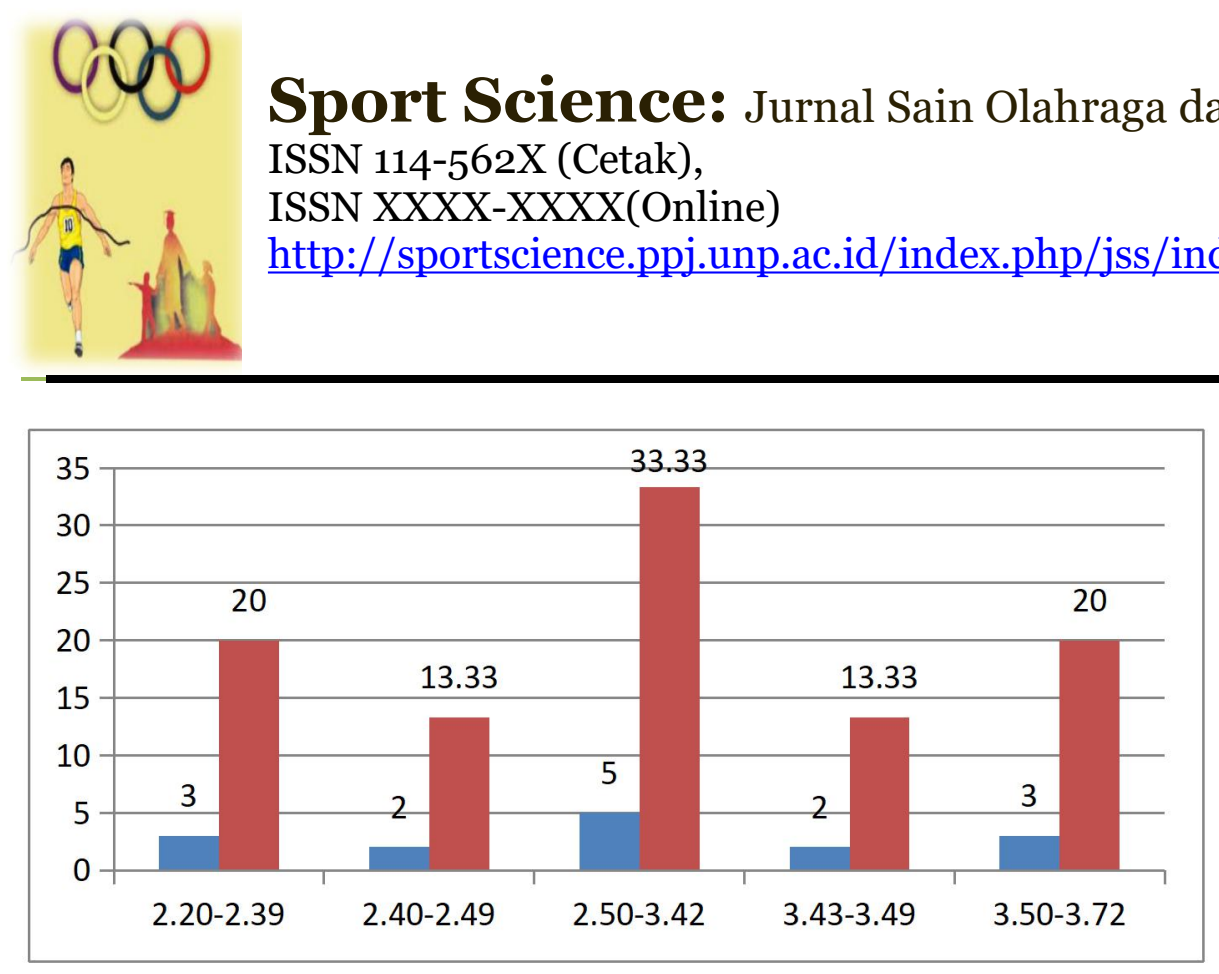

Grafik 1. Data Hasil Tes Awal Daya Ledak Otot Lengan Atlet karate Pendidikan Olahraga Universitas Negeri Padang

2. Data daya ledak otot lengan atlet karatePendidikan Olahraga Universitas Negeri Padang (Post Test)

Berdasarkan analisi terhadap data tes akhir maka pengaruh latihan beban menggunakan Bench Press terhadap daya ledak otot lengan atlet karate Pendidikan Olahraga Universitas Negeri Padang( Post Test) menunjukan hasil sebagai berikut: skor tertinggi 4.15 dan skor terendah adalah 2.80 dengan rata-rata3.48 dan standar deviasi 0.50 . Untuk lebih jelasnya akan dibuatkan table distribusi frekuensi dibawah ini.

Tabel 3. Data Hasil Tes Akhir Daya Ledak Otot Lengan Atlet karate Pendidikan Olahraga Universitas Negeri Padang.

\begin{tabular}{clcc}
\hline No & $\begin{array}{c}\text { Kelas Weight } \\
\text { Training }\end{array}$ & Frekuensi Absolut (Fa) & $\begin{array}{c}\text { Frekuensi } \\
\text { Relatif (Fr) }\end{array}$ \\
\hline 1 & $2.80-2.90$ & 2 & 13.33 \\
2 & $2.92-3.04$ & 2 & 13.33 \\
3 & $3.05-3.64$ & 5 & 33.33 \\
4 & $3.65-3.89$ & 2 & 13.33 \\
5 & $3.95-4.15$ & 4 & 26.67 \\
& Jumlah & 15 & $100 \%$ \\
\hline
\end{tabular}

Berdasarkan data distribusi frekuensi di atas, persentase dari 15 orang sampel ternyata sebanyak 2 orang sampel (13.33\%) memiliki daya ledak otot lengan dengan kelas Weight Training 2.80-2.90, kemudian sebanyak 2 orang sampel (13.33\%) memiliki daya ledak otot lengan dengan kelas Weight Training 2.92-3.04, selanjutnya ada 5 orang sampel (33.33\%) memiliki daya ledak otot lengan dengan kelas Weight Training 3.05-3.64, sedangkan 2 orang ampel (13.33\%) memilik daya ledak otot lengan dengan kelas Weight Training 3.65-3.89 dan sebanyak 4 orang sampel (26.67\%) memiliki daya ledak otot lengan dengan kelas Weight Training 3.95-4.15. Untuk lebih jelasnya dapat dilihat pada grafik berikut. 


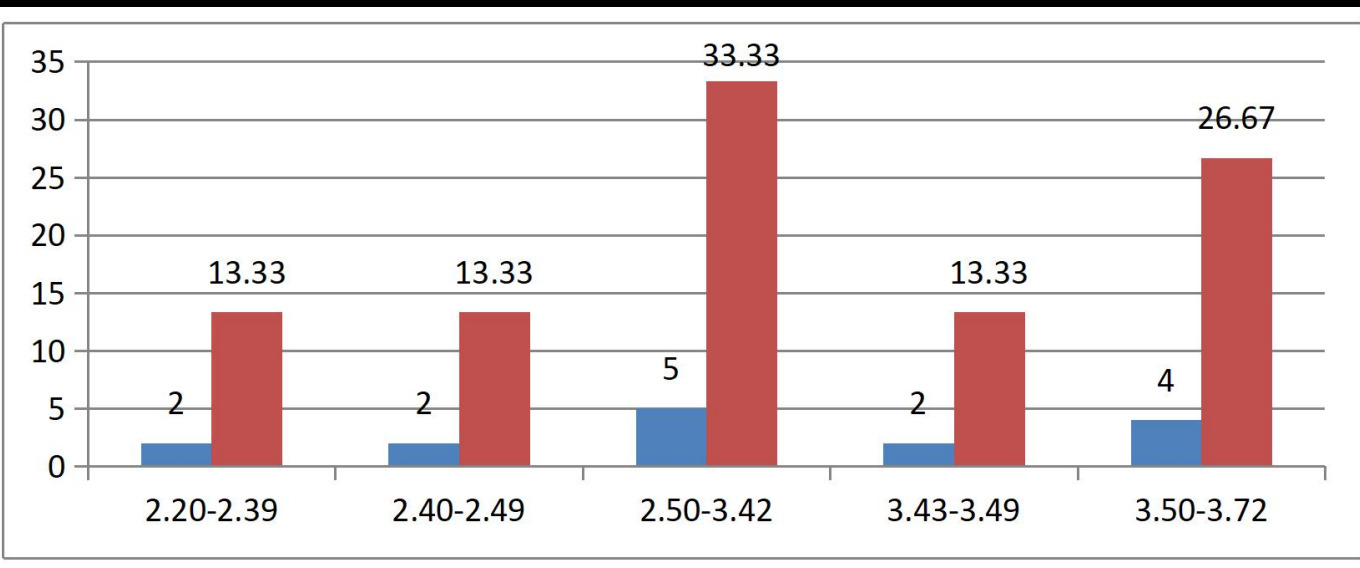

\section{Grafik 5. Data Hasil Tes Akhir Daya Ledak Otot Lengan Atlet karatePendidikan Olahraga Universitas Negeri Padang}

\section{B. Uji Persyaratan Analisis Dengan UjiLillefors}

Analisi uji normalitas data dilakukan dengan uji lillefors Dengan taraf nyata $(\alpha)=0.05$, kriteria penelitiannya adalah bahwa di tolak hipotsis nol jika $L_{\text {Hitung }}$ yang diperoleh dari data pengamatan melebihi $\mathrm{L}_{\text {tabel }}$ dan sebaliknya diterima hipotesis nol jikaa $\mathrm{L}_{\text {hitung }}$ yang diperoleh lebih kecil dari $\mathrm{L}_{\text {tabel, }}$ secara sederhana dapat digunakan rumus sebagai berikut

$\mathrm{H}_{\mathrm{a}}$ ditolak jika, $\mathrm{L}_{\text {hitung }}\left(\mathrm{L}_{\mathrm{h}}\right)>\mathrm{L}_{\text {tabel }}\left(\mathrm{L}_{\mathrm{t}}\right)$

$\mathrm{H}_{\mathrm{a}}$ diterima jika, $\mathrm{L}_{\text {hitung }}\left(\mathrm{L}_{\mathrm{h}}\right)<\mathrm{L}_{\text {tabel }}\left(\mathrm{L}_{\mathrm{t}}\right)$

Hasil analisis uni normalitas masing-masing variabel disajikan dalam bentuk tabel dibawah ini dan perhitungan lengkapnya dapat di lihat pada lampiran.

Tabel 5. Uji normalitas data dengan lillefors

\begin{tabular}{|l|l|l|l|l|}
\hline No & Latihan & Lo & Lt & Keterangan \\
\hline 1 & Pre test & 0,196 & 0.220 & Nomal \\
\hline 2 & Pos test & 0,202 & 0.220 & Normal \\
\hline
\end{tabular}

Pada tabel di atas dapat dilihat bahwa hasil $\mathrm{L}_{\mathrm{o}}$ variabel hasil daya ledak otot lengan atlet lebih kecil dari $\mathrm{L}_{\mathrm{t}}$, maka dapat disimpulkan bahwa data berdistribusi normal.

\section{Pengajuan Hipotesis}

Untuk menguju apakah hipotesis yang diajukan dalam penelitian ini diterima keberadaannya atau tidak maka dilakukan pengajuan data yang memakai uji-t pengujian hipotesis ini dapat dikemukakan sebagai berikut:

Dari analisis dilakukan, nilai thitung antara tes awal dan tes akhir dengan latihan beban menggunakan bench press terhadap daya ledak otot lengan atlet karate Pendidikan Olahraga UNP menunjukan angka sebesar 5,1376 selanjutnya nilai yang diperoleh di bandingkan dengan nilai tabel pada taraf signifikan0.05 dengan derajat $\mathrm{N}-1$ (14) ternyata nilai yang diperoleh adalah 2.14 hal ini menunjukan bahwa nilai thitung $(5,1376)>t_{\text {tabel }}(1.761)$ dengan demikian dapat disimpulkan bahwa hipotesis yang menyatakan terdapat pengaruh Weight Training terhadap daya ledak otot lengan atlet karate Pendidikan Olahraga Universitas Negeri Padang dapat diterima keberadaannya 


\section{Pembahasan}

Kecepatan kontraksi otot yang terkait (serabut otot lambat dan serabut otot cepat), besarnya beban yang digerakkan, kontraksi otot intra dan ekstra, panjang otot pada waktu kontraksi dan sudut sendi. Daya ledak otot lengan adalah kemampuan seseorang dalam mengarahkan kekuatan dengan cepat dalam waktu yang sangat singkat serta untuk memberikan momentum yang paling baik pada otot lengan dalam suatu gerakan yang cepat dalam melakukan aktifitas olahraga.Untuk menentukan hasil pengaruh daya ledak otot lengan ditentukan dengan menggunakan uji-t, dimana hasil yang ditemukan terdapat pengaruh yang signifikan Weight Training terhadap peningkatan daya ledak otot lengan atlet karate.

Hasil daya ledak otot lengan atlet sebelum dilakukan latihan beban menggunakan bench press dapat ditentukan bahwa dari 15 orang atlet, Melly Purnama sebesar 2.20 adalah atlet yang paling terendah hasil tesnya, kemudian Yola Syafitri sebesar 2.30,Nissa Amanda sebesar 2.30, Febricha Asri sebesar 2.40, Sandra Iriana sebesar 2.45, Melki gunawan sebesar 2.50, Zose Fadillah sebesar 2.90, Agusti Purnama sebesar 2.95, Pajin Putra sebesar 3.20, Rian solihin sebesar 3.43, Tono Abdillah sebesar 3.45, Gino Rizky sebesar 3.50, Putra Andika sebesar 3.55, Setiawan sebesar 3.60, Ariston sebesar 3.72 adalah atlet yang tinggi hasil tesnya.

Kemudian hasil daya ledak otot lengan sesudah dilakukan latihan beban menggunakan Bench Press dapat ditentukan bahwa dari 15 atlet, Sandra Iriana sebesar 2.80 adalah hasil yang paling rendah tesnya, kemudian Yola Syafitri sebesar 2.83, Nissa Amanda sebesar 2.92, Febricha Asri sebesar 2.95, Melly Purnama sebesar 3.05, Melki gunawan sebesar 3.05, Rian solihin sebesar 3.35, Agusti Purnama sebesar 3.65, Pajin Putra sebesar 3.65, Zose Fadillah sebesar 3.82, Ariston sebesar 3.88, Gino Rizky sebesar 3.95, Ober Putra Andika sebesar 4.06, Setiawan sebesar 4.14, Tono Abdillah sebesar 4.15 adalah atlet yang tinggi hasil tesnya.

Dari hasil diatas bahwa perbedaan kedua daya ledak otot lengan sebelum dan sesudah melakukan latihanbeban menggunakan Bench Press. Daya ledak otot lengan sesudah di berikan perlakuan dengan latihan beban menggunakan Bench Press Nampak jelas peningkatan. Dimana sebelum diberikan perlakuan dengan latihan beban menggunakan Bench Press atlet banyak pada daya ledak otot lengan yang kurang, sedangkan setelah diberikan perlakuan latihan beban menggunakan Bench Press atlet mendapatkan perubahan daya ledak otot lengan yangbaik.

Berdasarkan pendapat di atas dapat didefinisikan bahwa daya ledak otot lengan adalah kemampuan mengarahkan kekuatan otot lengan dengan cepat dalam waktu yang sangat singkat untuk memberikan momentum yang paling baik pada tubuh dalam suatu gerakan yang cepat untuk mencapai tujuan yang dikehendaki. Serta kenyataan bahwa latihaan beban merupakan bentuklatihan yang efektif untuk meningkatkan daya ledak.

Pemberian latihaan beban menggunakan Bench Press akan menyebabkan daya ledak otot lengan meningkat, maka secara otomatis latihan beban menggunakan Bench Press akan berpengaruh terhadap daya ledak ototlengan. Peneliti menyadari terdapat beberapa keterbatasan dalam pelaksanaan perlakuan dalam penelitian ini, walaupun sudah dicobauntukmengatasi kemungkinan gangguan terhadap variabel penelitian, tetapi pada kenyataannya sulit untuk menghindari munculnya permasalahan selama penelitian dilakukan antara lain: sampel ada yang tidak hadir ketika jadwal latihan sehingga harus diganti dengan hari lain. Melakukan kontrol secara ketat terhadap sampel, karena sampel mempunyai kesibukan masing-masing dalam kuliahnya. Perbedaaan hari saat pengambilan data dikarenakan Testee berhalangan hadir saat jadwal test dilakukan.

Kemudian terlihat dalam melakukan perlakuan masih ada yang kurang serius, tetapi peneliti berusaha memberi motivasi baik itu secara internal maupun eksternal dengan maksimal agar bisa melakukan dengan baik. Peneliti juga tidak bisa mengontrol aktifitas diluar dan gizi Testee. Selanjutnya sarana dan prasarana juga menentukan keberhasilan dalam pencapaian hasil latihan yang 
baik. Sarana dan prasarana yang memadai, baik secara kualitas dan kuantitas selain menambah motivasi Testee dalam melaksanakan latihan untuk mencapai suatu prestasi yang lebih baik.

\section{KESIMPULAN}

Dari hasil penelitian di atas maka dapat diambil kesimpulan bahwa terdapat pengaruh Weight Trainingterhadap daya ledak otot lengan atlet karate Pendidikan Olahraga Universitas Negeri Padang dengan $t_{\text {hitung }}(5,1376)>t_{\text {tabel }}(1.761)$ pada $\alpha=0.05$, dimana hasil rata-rata daya ledak otot lengan pada tes awal 2.96 sedankan tes akhir meningkat atau lebih jauh jaraknya menjadi 3.48 (meningkat 0.52 meter). Ini berarti terjadi peningkatan daya ledak otot lengan dengan menggunakan latihan Bench Press.

Mendapatkan daya ledak otot lengan yang bagus dapat dilakukan dengan cara latihan beban menggunakan Bench Press. Kepada atlet untuk dapat melakukan latihan beban menggunakanBench Pressuntuk mendapatkan daya ledak otot lengan yangbagus. Hasil daya ledak otot lengan yang bagus di pengaruhi oleh faktor internal dan faktoreksternal.

Atlet yang memiliki potensi otot lengan yang bagus agar dapat mempertahankannya, dan sebaliknya kepada atlet yang memiliki potensi daya ledak otot lengan yang kurang bagus agar lebih berlatih lagi untuk meningkatkan daya ledak ototlengannya. Pelatih disarankan agar dapat mengembangkan potensi daya ledak otot lengan atletnya kearah yang lebih baik dengan salah satu bentuk latihan Bench Press.

\section{DAFTAR RUJUKAN}

Abdul Wahid. (2007). Shotokan. Jakarta: Raja Grafindo persada

Bafirman, Apri Agus. (2008). Pembinaan Kondisi Fisik. Padang: Universitas Negeri Padang.

Fachreza, Welly. (2010). Pengaruh Metode Weight Training Terhadap Daya Ledak Otot Lengan. Padang: Universitas Negeri Padang.

Irawadi, Hendri. (2014) Kondisi Fisik dan Pengukuran. Padang: Universitas Negeri Padang.

Syafruddin, (2011).Dasar-dasar Kepelatihan Olahraga. Padang: DIP Proyek Universitas Negeri Padang..

Tim Statistik UNP. (2011). Statistik . Padang: Universitas Negeri Padang

Undang-undang Negara Republik Indonesia No.3 (2005). Sistem Keolahragaan Nasional. Bandung: Citra Umbara 